\title{
Potential of using EAHX for Low Energy Cooling in Nigeria
}

\author{
Julius Ojebode ${ }^{1}$ and Kassim Gidado ${ }^{2}$
}

\begin{abstract}
Earth-air heat exchangers (EAHX), also called ground tube heat exchangers, are a possible technique to reduce energy consumption for heating or cooling in buildings. The growing pressure for low energy and environmentally-sensitive building is likely to continue alongside the desire to have more efficient facilities management. Therefore there is need for greater interaction at the organization level between facilities management providers and designers to close the gap between philosophies. The hot dry climatic zone of Nigeria is characterized by a period of high temperature and low relative humidity between February and May. Between these months, the daily mean maximum indoor temperature of most buildings is about $37^{\circ} \mathrm{C}$ with low indoor air velocity.

Most occupants of the buildings in Nigeria have persistent and growing problems with the indoor environment due to high indoor temperature. Also they are characterized by poor design in relation to the climate, which requires a great deal of energy for cooling during climatic extremes. Other problems are poor natural ventilation, inadequate surface volume ratio and poor building orientation. This has led to negative consequence that affect the occupant's physiological comfort, capacity for mental and physical work, health and leisure. This research identifies technology that can be adopted in this climatic region to minimize the use of energy for cooling, improve occupant's comfort and enhance low energy. The objective is to reduce overdependence on electricity demand and energy use in residential buildings in Nigeria.
\end{abstract}

Keywords: Earth-Air Heat Exchanger, Cooling, Energy, Environment, Facilities Management, Heating, Indoor and Outdoor Temperature.

\section{Introduction}

Nigeria is the most populous country in Africa. Its population currently stands at 150 million people and is expected to grow to 230 million by 2030. The steady economic and population growth is putting significant strain on the country's electricity supply and distribution infrastructure, which is currently meeting less than $50 \%$ of demand. More than $64 \%$ of Nigeria's electricity is generated from fossil fuel and about $34 \%$ from hydro plants (World Bank 2001).

1 Research Student, School of Environment and Technology, University of Brighton, Cockcroft Building, Lewes Road, Brighton, BN2 4GJ, UK . E-mail: juliusojebode@yahoo.com.

2 Principal lecturer, School of Environment and Technology, University of Brighton, Cockcroft Building, Lewes Road, Brighton, BN2 4GJ, UK , E-mail: K.I.Gidado@brighton.ac.uk 
Energy consumption of the building sector is high. Although figures differ from country to country, buildings are responsible for about $30-40 \%$ of the total energy demand. However, energy needs for cooling increases in a dramatic way. The increase of family income and information technology has led to an increasing demand for cooling in the residential and commercial building sectors. Cooling is a significant user of energy in buildings, and its importance as a contributor to greenhouse emissions is enhanced by the fact that these systems are usually electrically driven. High cooling requirements can result in high electrical demands, with consequent problems for utility companies (IEA,1995; Santamouris 1996; Heap 2001).

According to Central Bank of Nigeria (2010), Residential consumption accounted for 56.3 percent of total electricity consumption, while commercial and street - lighting and Industrial consumption accounted for 25.7 and 18.0 percent of the total respectively. The rule of thumb for any developed industrial nation is that at least 1 gigawatt (i.e. 1,000 megawatts) of electricity generation and consumption is required for every 1 million head of population. Nigeria's per capita electricity consumption is amongst the lowest in the world and far lower than many other African countries. Nigeria's per capita electricity consumption is just 7\% of Brazil's and just 3\% of South Africa's. As at August 2010, the peak generation supplied by Nigeria's PHCN was just 3,804 MW for a population of 150 million people. (Road Map for Power Sector Reform in Nigeria 2010).

However, Nigeria needs to start considering alternative low energy cooling strategies and technologies that have potential to reduce energy consumption and cost associated with the use of air conditioning. Passive system have the potential to reduce operational energy consumption for cooling buildings in the tropical climate, help reduce rising energy demands and the associated greenhouse gas emissions that is detrimental to the planet (Ahmed and Gidado 2008). In hot climates, such as Nigeria, using EAHX for low energy cooling can reduce energy consumption whilst providing cost savings and maintaining a healthy and comfortable environment for people.

\section{Building Cooling Demand In Nigeria}

Increased living standards in the developing world using non-climatically responsive architectural standards have made air conditioning quite popular. Importantly, this has increased energy consumption in the building sector. Actually there are more than 240 million air conditioning units and 110 heat pumps installed worldwide according to the International Institute of Refrigeration (IIR) (IIR, 2002). IIR's study shows that the refrigeration and air conditioning sectors consume about $15 \%$ of all electricity consumed worldwide (IIR, 2002).

In hot climates, such as Nigeria, commercial and residential buildings with appropriate heat and solar protection and careful management of internal loads may reduce their cooling load down to $5 \mathrm{kWh} / \mathrm{m} 2 /$ year, (Santamouris and Daskalaki, 1998), while buildings of low quality environmental design may present loads up to $450 \mathrm{kWh} / \mathrm{m} 2 / \mathrm{y}$ (Santamouris, 1997). Under the same climatic conditions and when internal gains are not important, such as in residential buildings, the use of air conditioning may be completely avoided when efficient solar and heat protection as well as heat modulation techniques are used.

Landscaping is a natural and beautiful way to keep home comfortable and reduce energy consumption by up to $25 \%$. Apart from adding aesthetic value and environmental quality 
to home, trees, shrub or vine can help deliver effective shade and act as windbreak. A well designed home can reject overhead heat to reduce the energy spent for cooling. Low quality windows can cause air conditioner to work two or three times harder. In warm climates, it is advisable to use windows with special coating that will help to reduce heat gain. Replacing single paned windows with double-paned windows can help to reduce heat gain and reduce the energy spent on cooling. (Uyigue, 2008 and Ahmed, 2009).

Naturally ventilated buildings are likely to overheat more frequently in extreme conditions and air conditioning systems may fail more regularly. It is probable that full air conditioning will be demanded in more buildings to control summer temperatures and humidity, leading to an increase in energy usage. It is imperative that designs for future buildings and major refurbishments account for a changing climate to ensure that buildings can provide comfortable and healthy internal environments over their lifetime, whilst minimising energy use and greenhouse gas emissions.

\section{Earth-Air Heat Exchanger Technology}

Ground cooling is the dissipation of the excess heat of a building to the ground. Air is cooled by circulating through underground pipes, that play the role of earth-to-air heat exchangers and is then injected inside the building. Earth-to-air heat exchangers are suitable for cooling of buildings and so could play a significant role in reducing $\mathrm{CO}_{2}$ emissions (Tzaferis,1992). Other advantages are their simplicity, high cooling potential, low capital, operational and maintenance cost. A large variety of buildings with earth-to-air heat exchangers have been designed and monitored, and the performance of the systems have been proven very high (Pfafferrott, 2007). Ground cooling systems have been used successfully in many housing projects (Burton \& Fjearem, 2004 and Kaan, 2006). In particular, the use of earth-to-air heat exchangers in a new housing development in Portugal has contributed to a reduction in the cooling needs by $95 \%$ compared to an airconditioned building, and the mean cost per building was quite low, at close to 7500 Euros/ house ( Burton \& Fjearem, 2004). Similar results have been obtained in Greece where earth-to-air heat exchangers have been used in a housing complex to provide cooling during the summer period (Kaan, 2006).

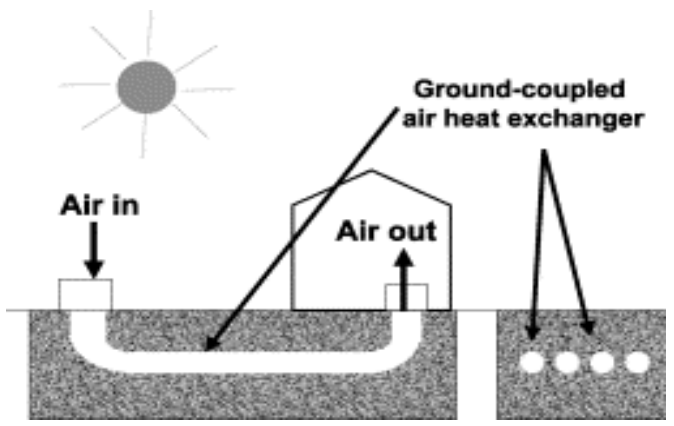

Figure 1. Typical Example of Earth-Air heat exchanger

In hot regions, where cooling is of interest, the natural temperature of the soil in summer is usually too high for serving as a cooling source. However, it is possible by very simple means to lower the soil temperature well below the natural temperature characteristics of a given location. In order to cool the soil it is necessary to eliminate or minimize the heating of the soil by the sun, by shading, while enabling cooling by evaporation from the earth surface (Givoni, 2007). 
The consumption of energy in buildings for cooling and heating purpose has increased considerably. The passive heating as well as cooling technique in which either heat is removed or given to buildings from a natural heat sink like earth has become popular today. In the operation of an earth-air heat exchanger, freely available energy, stored inside the earth has been used for heating and cooling purposes. Thus, less amount of conventional energy is required, which leads to a decrease in the mitigation of $\mathrm{CO}_{2}$ in the environment. (Ahmad, 2010).

Research has established that subsurface soil temperature is lower than ambient air temperature in summer and higher than ambient air temperature in winter, this is as a result of high soil thermal mass that store high percentage of the heat gain on daily basis to less than $30 \mathrm{~cm}$ below the surface (Labs, 1989).

The potential of earth-air heat exchanger has been established in moderate climates of Europe, however not much research has been carried out in hot climates because of the claim that the potential is low due to higher soil temperature in summer. Recent research has shown that the potential of the system in hot climates may however be improved using various soil cooling strategies to lower the natural subsurface soil temperature such as shading, surface irrigation, surface treatment using plants and pebbles. ( Ahmed \& Gidado, 2008, Givoni, 2007, Kasuda, 1975).

Tropical climate is characterised by high ambient temperatures and solar radiation, a combination of these and other factors causes thermal discomfort in buildings. The common approach to maintaining comfortable thermal environment in buildings in tropical climates is using mechanical air-conditioning systems. In buildings where mechanical cooling is not affordable, buildings are occupied in harsh conditions which affect performance especially in offices and other work environments. High energy demand is needed to operate and maintain mechanical systems continuously over long period of time during a day. With the rapid increase in population and economic growth of countries in the Tropical regions such as Nigeria, it is becoming inevitable that passive and low energy strategies must be used as suitable alternatives. Passive system have the potential to reduce operational energy consumption for cooling buildings in the tropical climate, help reduce rising energy demands and the associated greenhouse gas emissions that is detrimental to the planet.(Ahmed and Gidado, 2008).

The main advantages of the system are its simplicity, high cooling and pre-heating potential, low operational and maintenance costs, saving of fossil fuels and related emissions. Pre-heated fresh air supports a heat recovery system and reduces the space heating demand in winter. In summer, in combination with a good thermal design of the building, the EAHX can eliminate the need for active mechanical cooling and airconditioning units in buildings, which will result in a major reduction in electricity consumption of a building if the EAHX is designed well. EAHXs are hence a passive cooling option in moderate climates. (Pfafferott, 2003).

A study of residential buildings in Nigeria shows that most occupants of the buildings have persistent and growing problems with the indoor environment due to high indoor temperature. Most buildings are characterized by poor design in relation to the climate, which requires a great deal of energy for cooling during climatic extremes. Other problems are poor natural ventilation, inadequate surface- volume ratio and poor building orientation. This has led to negative consequence that affect the occupant's physiological 
comfort, capacity for mental and physical work, health and leisure (Akande, 2010). Reduction of energy consumption in domestic buildings and commercial settings has been a major aim worldwide in view of the limiting of the growing demand for electricity and the efforts to reduce CO 2 emissions. (Adelaja, 2008).

\section{Potential Energy Demand For Cooling In Nigeria}

To illustrate the magnitude of the potential future increase in energy demand for cooling in Nigeria, this analysis compared the potential cooling demand in Nigeria (the largest population area with a hot climate in a developing country) to the demand for the entire US (the country with the greatest use of air conditioning among developed countries).

The analysis compared the product of the population and cooling degree days for Nigeria (both from Table 1 with the product of the population in the US (296.5 million in 2005, from US Census Bureau, 2007) and a population-weighted national average of cooling degree days 882 .

The product of the population and cooling degree days for Nigeria is equal to 466,650 million person-cooling-degree-days. The analogous product for the entire US is equal to 261,513 million person-cooling-degree-days. Thus, the potential cooling demand in USA is about $58 \%$ of the demand for the entire Nigeria.

Whether the potential cooling demand in Nigeria will translate into energy consumption for cooling is not clear. Differences in energy infrastructure, size and occupancy density of dwellings, sustainability concerns, desirable temperature, and diurnal use of air conditioning (in addition to income and energy cost) will influence the energy use for cooling in Nigeria. Nevertheless, the potential for a huge increase in energy use remains.

As has been alluded to throughout this thesis, the potential for EAHX within the Nigeria cooling market is substantial. With the availability of attractive schemes and grants, along with an increased awareness of the technologies available and their ability to reduce our carbon emissions, ground source heat pump systems should thrive within the Nigeria cooling market.

Table 1: Average Annual Cooling Degree Days(CDD) for Three Countries

\begin{tabular}{|c|c|c|}
\hline Country & Population & CDD \\
\hline Nigeria & $150 \mathrm{~m}$ & 3,111 \\
\hline USA & $296.5 \mathrm{~m}$ & 882 \\
\hline United Kingdom & $61 \mathrm{~m}$ & 66 \\
\hline
\end{tabular}

\section{Conclusion}

Despite increasing use elsewhere, earth-air heat exchangers are a relatively unfamiliar technology in Nigeria, although the performance of systems is now such that, properly designed and installed, they represent a very carbon-efficient form of cooling in buildings. As climate control is one of the largest sources of energy use in buildings, it is important to balance energy savings against occupant needs. However, although modifying the 
conditions at which we maintain the indoor thermal environment may result in both energy and cost savings.

For sustainable economic growth and development, energy conservation should be a preferred energy supply option in the country. However, for serious and beneficial energy conservation in the buildings sector, the government needs to take some necessary steps in exploiting Earth-Air Heat exchanger for cooling in residential buildings as this will reduce the energy consumption in the country.

Appropriate resource management is a key requirement for the cooling system towards addressing global concerns of man's growing impact on the environment. The Earth-Air Heat Exchanger for low energy cooling strategies discussed in this dissertation when effectively implemented, enable energy conservation and promote sustainability. 


\section{References}

ADELAJA, A., DAMISA, O., OKE, S., AYOOLA, A AND AYEYEMITAN, A. (2008) Survey of the energy consumption and demand in Tertiary institution. Maejo International journal of science and technology.

AHMAD, N., TIWARI, G., SINGH, A (2010) Heating/cooling potential and carbon credit earned for dome shaped house. International journal of energy and environment Volume 1, Issue 1, 2010 pp.133-148.

AHMED, A, KENNETH IP, MILLER, A AND GIDADO, K. (2009) thermal performance of earth-air heat exchanger for reducing cooling energy demand of office buildings in the united kingdom Eleventh International IBPSA Conference Glasgow, Scotland

AHMED, A AND GIDADO, K (2008) The use of Earth-Air Heat Exchanger for improving building comfort conditions in the Tropical Climate

AHMED, A, KENNETH IP, MILLER, A AND GIDADO. (2007)The potential of earth-air heat exchangers for low energy cooling of buildings. The 24th Conference on Passive and Low Energy Architecture

AHMED, A, GIDADO, K, (2008) Evaluating the potential of Renewable energy technologies for buildings in Nigeria. Association of Researchers in Construction Management. 24 ${ }^{\text {th }}$ annual ARCOM conference, 1-3 September 2008

AKANDE, A. (2009).Passive design strategies for residential buildings in a hot dry climate in Nigeria.

BURTON, S., ADAM FJEARE M. (2004) Cooling in housing in Southern Europe without chillers, in: Proceedings of the 25th AIVC Conference, Prague, Czech Republic.

GIVONI, B. (2007) Cooled soil as a cooling source for buildings. UCLA, Los Angeles, CA, USA BGU, Beer Sheva, Israel.

INTERNATIONAL ENERGY AGENCY (1995): Energy Conservation in Building and Community System programme: Annex 28 - Low Energy Cooling: Review of Low Energy Cooling Technologies. Subtask 1Report. December 1995

HEAP, R.D., 2001, Refrigeration and air conditioning - theresponse to climate change, Bulletin of the IIR-2001-5

INTERNATIONAL INSTITUTE OF REFRIGERATION,IIR (2002). Industry as a partner for sustainable development refrigeration, report published by, Paris, France

KAAN, H. (2006) Demohouse, design and management options for housing, in: Proceedings of the Conference Eco-buildings, Berlin, Germany.

KASUDA, T. (1975) The effects of ground cover on Earth temperature. IN 
MORELAND, F. L. (Ed.) The use of earth covered buildings. Forth Worth, Texas, U.S Government Printing Office.

LABS, K. (1989) Earth Coupling. IN COOK, J. (Ed.) Passive Cooling. London, MIT Press.

PFAFFERO TT, J., WALKER-HERTKORN, S. (2007) Ground cooling-recent progress, London.

PFAFFEROTT, J. (2003). Evaluation of earth-to-air heat exchangers with a standardised method to calculate energy efficiency. Fraunhofer-Institute for Solar Energy Systems, Heidenhofstr. 2, 79110 Freiburg, Germany.

SANTAMOURIS, M., MIHALAKAKOU, G AND ASIMAKOUPOLOS, D. (1997) On the coupling of thermostatically controlled buildings with ground and night ventilation passive dissipation techniques, Solar Energy 60 (3-4) (1997), pp. 191197.

SANTAMOURIS, M. (2006) Ventilation for comfort and cooling, the state of the art, in: M. SANTAMOURIS, P. WOUTERS, (2006) Ventilation in Buildings- The State of the Art, Earth scan Publishers, London, UK.

SANTAMOURIS, M., ASIMAKOPOULOS, D., 1996, Passive Cooling of Buildings, James\&James Ltd., London, U.K., 472 p.

UYIGUE, E (2008) The concept of energy efficiency. Community Research and development centre (CREDC) Benin City, Nigeria.

WORLD BANK (2001) World development indicators. Washington, DC, World Bank. 